\title{
European Harmonized Standard
}

National Cancer Institute

\section{Source}

National Cancer Institute. European Harmonized Standard. NCI Thesaurus. Code

C142542.

A document of guidelines for activities or their results that is established as a European Norm, approved and recognized by all Member States and published in the Official Journal of the European Communities (OJEC). 